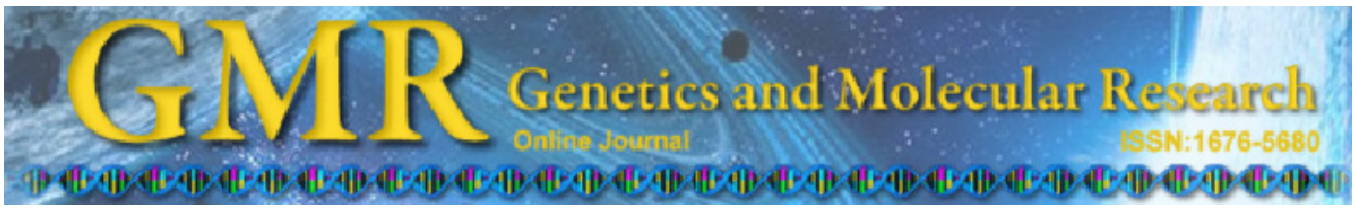

\title{
Evaluation of HPFH and $\delta \beta$-thalassemia mutations in a Brazilian group with high Hb F levels
}

\author{
G.C.S. Carrocini ${ }^{1}$, L.S. Ondei ${ }^{2}$, P.J.A. Zamaro ${ }^{1}$ and \\ C.R. Bonini-Domingos ${ }^{1}$ \\ ${ }^{1}$ Laboratório de Hemoglobinas e Genética das Doenças Hematológicas, \\ Departamento de Biologia, \\ Universidade Estadual Paulista "Júlio de Mesquita Filho", \\ São José do Rio Preto, SP, Brasil \\ ${ }^{2}$ Universidade Estadual de Goiás, Unidade Universitária de Porangatu, \\ Porangatu, GO, Brasil
}

Corresponding author: G.C.S. Carrocini

E-mail: giselecristine_bio@yahoo.com.br

Genet. Mol. Res. 10 (4): 3213-3219 (2011)

Received January 12, 2011

Accepted July 5, 2011

Published December 21, 2011

DOI http://dx.doi.org/10.4238/2011.December.21.3

\begin{abstract}
Fetal hemoglobin (Hb F) is characteristic of the fetal development period. However, in some genetic conditions, such as hereditary persistence of fetal hemoglobin (HPFH) and deltabeta thalassemia ( $\delta \beta$-thalassemia), $\mathrm{Hb} \mathrm{F}$ continues to be produced in adulthood. We evaluated the frequency of two mutations of HPFH, HPFH-1 and HPFH-2 African, and two mutations in $\delta \beta$-thalassemia, Sicilian and Spanish, in a Brazilian population. Peripheral blood samples were collected from adults from hospitals and blood centers in southeast and northeast Brazil. These individuals were healthy and without complaints of anemia, but had increased Hb F. Samples were submitted to electrophoretic and chromatographic analyses to quantify $\mathrm{Hb} \mathrm{F}$ values and, subsequently, to molecular analyses to verify the mutations. In the molecular analysis, 16 of the 60 samples showed a heterozygous profile for the HPFH mutations, two for HPFH-1 and 14 for HPFH-2. In the same sample set, three were heterozygous for
\end{abstract}


Spanish $\delta \beta$-thalassemia and none were heterozygous for Sicilian $\delta \beta$ thalassemia. The $\mathrm{Hb} \mathrm{F}$ values in the HPFH-2 heterozygotes differed from those previously reported for this mutation. In this group, the HPFH mutations were more frequent than the $\delta \beta$-thalassemia mutations. The finding of these mutations in this Brazilian population reflects the mixing process that occurred during its formation.

Key words: $\mathrm{Hb}$ F; HPFH-1; HPFH-2; Spanish $\delta \beta$-thalassemia; Sicilian $\delta \beta$-thalassemia

\section{INTRODUCTION}

Fetal hemoglobin $(\mathrm{Hb} F)$ is a globular protein composed of two $\alpha$ - and two $\gamma$-globin chains $\left(\alpha_{2} \gamma_{2}\right)$. The levels of $\mathrm{Hb} F$ usually decline a few months after birth, to less than $1 \%$ of total hemoglobin. However, in some genetic conditions, a high level of this $\mathrm{Hb}$ continues in adulthood (Stamatoyannopoulos and Nienhuis, 1994; Weatherall and Clegg, 2001).

Hereditary persistence of fetal hemoglobin (HPFH) is a condition resulting from lack of change from gamma to $\beta$-globin synthesis, reflected by a substantial production of $\gamma$ globin, and therefore, of $\mathrm{Hb} \mathrm{F}$ (Nussbaum et al., 2008). This condition is associated either with the occurrence of single-point mutations in the promoter region of two $\gamma$ chains, which lead to an increased rate of $\gamma^{\mathrm{G}}$ - and $\gamma^{\mathrm{A}}$-gene transcription, or $\beta$-globin gene cluster deletions, which remove the $\delta$ - and $\beta$-globin genes (Hoyer et al., 2002; Gibney et al., 2008; Grosso et al., 2008).

Deletions in HPFH are associated with the removal of silencer elements in the region between $\gamma$ - and $\delta$-globin genes or the removal of enhancer elements in the proximity of the $\gamma$-globin genes (Weatherall, 2001). Heterozygous carriers of HPFH present $\mathrm{Hb} F$ levels ranging from 16.0 to $30.0 \%$ and normal red blood cells. The HPFH mutations are related to different ethnic backgrounds and include seven deletion mutations, among them Black, Ghanaian, Indian, Vietnamese, Thai, Italian, and Sicilian types (Huisman et al., 1996).

Delta-beta thalassemia ( $\delta \beta$-thalassemia) is characterized by the persistent expression of $\gamma$-globin genes in adults in association with decreased or absence of $\delta$ - and $\beta$-globin gene expression, leading to increased $\mathrm{Hb} \mathrm{F}$ concentrations, and presence of hypochromic and microcytic erythrocytes (Forget, 1998; Weatherall and Clegg, 2001). $\delta \beta$-thalassemia is characterized by the occurrence of large deletions involving the $\delta$ - and $\beta$-globin genes (Hoyer et al., $2002)$. Heterozygous carriers of $\delta \beta$-thalassemia $\left(\delta \beta^{\circ}\right)$ show $\mathrm{Hb} \mathrm{F}$ levels ranging from 4.0 to $18.6 \%$. The $\delta \beta$-thalassemia mutations also are related to different ethnic groups and include several deletion mutations such as Turkish, German, Japanese, Black, Sicilian, and Spanish types, among others (Huisman et al., 1996).

Elevated $\mathrm{Hb} \mathrm{F}$ levels are known to improve the clinical manifestations of the two largest known hemoglobin changes: sickle cell disease and $\beta$-thalassemia. In sickle cell disease, the $\mathrm{Hb} \mathrm{F}$ concentration and distribution among the red blood cells are the main genetic modulators of the disease, whereas high levels of this hemoglobin dilute the amount of $\mathrm{Hb} \mathrm{S}$, inhibiting or delaying the polymerization process, which results in reduced disease severity (Steinberg, 2009). In homozygous $\beta$-thalassemia, increased production of $\gamma$ chains helps in reducing the imbalance of $\alpha$ and non- $\alpha$ chains and increasing total hemoglobin levels (Galanello and Cao, 1998; Thein, 2005). In subjects without hemoglobin alterations, $\mathrm{Hb}$ F can be found 
in high concentrations, which makes the expression pattern of $\gamma$ genes an important target in a range of studies.

The aim of this study was to determine the frequency of two HPFH mutations, HPFH1 (Black) and HPFH-2 (Ghanaian), and two $\delta \beta$-thalassemia mutations, Sicilian and Spanish, by Gap-PCR and compare respective mutations with $\mathrm{Hb} F$ concentrations in adults, who were previously diagnosed with increased $\mathrm{Hb} \mathrm{F}$.

\section{MATERIAL AND METHODS}

\section{Study group}

Sixty peripheral EDTA-blood samples of adult individuals, who had no clinical symptoms of anemia and whose $\mathrm{Hb} \mathrm{F}$ was increased, were collected and analyzed after obtaining informed consent from hospitals and blood centers in southeast and northeast Brazil. The study was approved by the Research Ethics Committee of São Paulo State University, UNESP. Samples were separated into two groups according to $\mathrm{Hb} F$ concentrations: Group I, with $\mathrm{Hb}$ F ranging from 2.0 to $15.0 \%$ (34 samples) and Group II, with $\mathrm{Hb} \mathrm{F}$ levels above $15.0 \%$ (26 samples). The classification of samples into these groups was established according to the variation of $\mathrm{Hb} \mathrm{F}$ concentrations described in the literature for mutations of $\delta \beta$-thalassemia, 4.0 to $18.6 \%$, and HPFH deletions, 16.0 to $30.0 \%$ (Huisman et al., 1996).

\section{Hemoglobin analyses}

All samples were submitted to conventional hemoglobinopathy diagnosis methods, which included globular osmotic resistance in $0.36 \% \mathrm{NaCl}$ (Silvestroni and Bianco, 1975), erythrocyte morphology analysis (Bonini-Domingos, 2006) and electrophoresis at alkaline $\mathrm{pH}$ (Marengo-Rowe, 1965). In addition to these analyses, electrophoresis on agar-phosphate, $\mathrm{pH}$ 6.2 (Vella, 1968) and analyses by HPLC (Variant Bio-Rad) to obtain quantitative $\mathrm{Hb}$ values, were carried out. The samples were also subjected to electrophoresis of polypeptide chains in acidic $\mathrm{pH}$ (Alter et al., 1980) and quantification of $\gamma^{\mathrm{G}}$ - and $\gamma^{\mathrm{A}}$-globin chains by densitometry (Densitometer CELM), in order to evaluate the percentage content.

\section{Molecular analyses}

The DNA extraction from peripheral whole blood was performed by phenolchloroform (Pena et al., 1991) and molecular analysis by Gap-PCR (Craig et al., 1994). The choice of mutations evaluated in this study is justified by the fact that the technique of Gap-PCR is functional for the deletions in which breakpoints are already well defined (Old, 2003). Three primers used for the analysis of mutations, HPFH-1 (A1: 5'-AGAATGT CACACTTAGAATCTG-3'; A2: 5'-CACTTTAATTCTGGTCTACCTGAA-3'; A3: 5'-ACT GTGATGTTGGAAATGGAC-3'), HPFH-2 (B1: 5'-GACATGGACTATTGTTCAATGA-3'; B2: 5'-TGCTATGCCAACTCACTACC-3'; B3: 5'-TTTATATATGAAATGCTACTGATT-3') and Sicilian $\delta \beta$-thalassemia (F1: 5'-TTGGGTTTCTGATAGGCACTG-3'; F2: 5'-GTGT CACCCATTAATGCCTTGTAC-3'; F3: 5'-TAGATCCCTTTGCCATTATG-3'), and analysis protocols were described by Craig et al. (1994). Three primers used for the analysis of 
Spanish $\delta \beta$-thalassemia (N1: 5'-ATGGGTATTTCACTTGTTAT-3'; N2: 5'-ACTTTGTCT GTTAATTCAA-3'; N3: 5'-ACTGTGGAGCCCCTTTCTG-3') mutation were described by Vives-Corrons et al. (1991) and analysis protocols were described by Craig et al. (1994). The amplicons were eletrophoresed on 1.2\% agarose gel containing ethidium bromide and photographed under UV light through Image Capture System L-PIX Touch (Loccus Biotechnology). The size of the fragments obtained after amplification for the mutations analyzed are summarized in Table 1.

\begin{tabular}{lccc} 
Table 1. Sizes of the fragments after reaction amplification for the mutations analyzed. \\
\hline Fragment size & Normal homozygous & Heterozygote & Mutant homozygous \\
\hline HPFH-1 & $1616 \mathrm{bp}$ & $1616+1193 \mathrm{bp}$ & $1193 \mathrm{bp}$ \\
HPFH-2 & $2206 \mathrm{bp}$ & $2206+1950 \mathrm{bp}$ & $1950 \mathrm{bp}$ \\
Sicilian $\delta \beta$-thalassemia & $1585 \mathrm{bp}$ & $1585+1150 \mathrm{bp}$ & $1150 \mathrm{bp}$ \\
Spanish $\delta \beta$-thalassemia & $685 \mathrm{bp}$ & $685+299 \mathrm{bp}$ & $299 \mathrm{bp}$ \\
\hline
\end{tabular}

\section{Statistical analyses}

We used the chi-square test $\left(\chi^{2}\right)$ and the $t$-test for parametric data and the MannWithney test for nonparametric data. The software used in the analysis was Statistica 8.0 (Statsoft ${ }^{\mathrm{TM}}$ ). P values less than 0.05 were considered to be statistically significant.

\section{RESULTS}

Among the 60 samples, $51.67 \%$ ( 31 samples) of individuals were female and $48.33 \%$ (29 samples) were male subjects. The average values for $\mathrm{Hb} \mathrm{F}$ in respect to gender were not significantly different $(\mathrm{P}=0.94)$, since these values were equal to $16.64 \pm 11.96 \%$ for women and $16.98 \pm 11.45 \%$ for men.

In the groups studied, the average values of $\mathrm{Hb} \mathrm{F}$ were higher in Group II ( $28.88 \pm$ $5.84 \%)$ than Group I $(7.56 \pm 3.59 \%)$. In relation to the classical tests for diagnosis of hemoglobinopathies, both groups showed samples with positive osmotic resistance and microcytic and hypochromic red blood cells with mild to moderate alterations.

The results of diagnostic tests for hemoglobinopathies were statistically analyzed and the comparison of the groups showed a significant difference between them in erythrocyte morphology $\left(\mathrm{P}=0.01, \chi^{2}=8.94\right)$. Groups I and II differed in relation to the presence of mild morphological alterations $\left(\mathrm{P}=0.003, \chi^{2}=8.554\right)$. In Group I, two samples $(5.88 \%)$ presented these alterations, whereas in Group II these changes were found in nine samples (34.61\%). There were no significant differences between groups regarding the presence of moderate alterations $(\mathrm{P}=0.14687)$ and normal erythrocytes $(\mathrm{P}=0.237)$.

The results of polypeptide chain electrophoresis acid $\mathrm{pH}$ allowed for the quantification of globin chains $\gamma^{\mathrm{A}}$ and $\gamma^{\mathrm{G}}$, in order to evaluate their percentage content. The majority of samples had higher percentages of $\gamma^{\mathrm{A}}$ chains in relation to $\gamma^{\mathrm{G}}$ chains. However, these differences did not allow for determination of the genotype of the individual, and thus, highlighted the need for molecular studies for such evaluation.

Of the 60 samples analyzed, 19 (31.67\%) showed the investigated mutations. For the 
HPFH mutations, 16 individuals (26.67\%) presented heterozygous status, one sample $(1.67 \%)$ belonging to the Group I and $15(25.0 \%)$ from Group II. Of these 16 samples, two (12.5\%) were heterozygous for HPFH-1, both in Group II, and 14 (87.5\%) were heterozygous for HPFH-2, one in Group I and 13 in Group II. For $\delta \beta$-thalassemia mutations, we found three $(5.0 \%)$ heterozygotes for Spanish $\delta \beta$-thalassemia. In contrast, there were no heterozygous samples for the Sicilian $\delta \beta$-thalassemia.

The two heterozygotes for HPFH-1 showed Hb F levels equivalent to 22.0 and $29.0 \%$, which are close to the $\mathrm{Hb} F$ levels found in the literature for this mutation. Among the 14 samples heterozygous for HPFH-2, only one had levels of $\mathrm{Hb} \mathrm{F}(25.9 \%)$ consistent with data from the literature for this mutation. Seven samples showed $\mathrm{Hb} F$ levels higher than those found in the literature, ranging from 30.3 to $38.1 \%$, and six samples showed $\mathrm{Hb} F$ levels lower, ranging from 10.0 to $21.2 \%$. Hb F levels were compared between the heterozygotes for evaluated HPFH mutations and those individuals without such mutations. Statistical analyses showed significant differences $(\mathrm{P}<0.0001)$ in the mean values of $\mathrm{Hb} \mathrm{F}$ in heterozygotes $(26.42 \pm$ $7.64 \%)$ in relation to normal subjects $(13.29 \pm 9.55)$.

The three individuals heterozygous for the Spanish $\delta \beta$-thalassemia mutation showed $\mathrm{Hb} \mathrm{F}$ levels equivalent to $9.6,9.8$ and $10.7 \%$, corroborating data from the literature regarding the concentrations of $\mathrm{Hb} \mathrm{F}$ for this mutation.

Table 2 shows the minimum and maximum $\mathrm{Hb} \mathrm{F}$ values found in heterozygous samples for both HPFH and Spanish $\delta \beta$-thalassemia mutations, compared with the values found in the literature for the same mutations.

$\begin{aligned} & \text { Table 2. Comparison between the minimum and maximum Hb F values (\%) found for the HPFH-1 and HPFH-2 } \\
& \text { mutations compared with data from literature. }\end{aligned}$
\begin{tabular}{lcc} 
Mutation & $\begin{array}{c}\text { Min-Max values of Hb F found in } \\
\text { heterozygous samples (\%) }\end{array}$ & $\begin{array}{c}\text { Min-Max values of Hb F found } \\
\text { in the literature* }\end{array}$ \\
\hline HPFH-1 (Black) & $22.0-29.0$ & $21.4-28.2$ \\
HPFH-2 (Ghanaian) & $10.0-38.1$ & $21.6-27.2$ \\
Spanish $\delta \beta$-thalassemia & $9.6-10.7$ & $5.0-13.0$
\end{tabular}

Min-Max = minimum and maximum values. *Huisman et al., 1996.

\section{DISCUSSION}

According to the literature, heterozygotes for HPFH mutations have $\mathrm{Hb}$ F levels between 16.0 and $30.0 \%$ and between 4.0 and $18.6 \%$ for $\delta \beta$-thalassemia mutations (Huisman et al., 1996). The results of this study demonstrated that Brazilian individuals with increased $\mathrm{Hb}$ $\mathrm{F}$ may have $\mathrm{Hb}$ levels ranging from 22.0 to $29.0 \%$ for HPFH-1 mutations and 10.0 and $38.1 \%$ for HPFH-2 mutations. These results show a variation in the Hb F levels in heterozygotes for HPFH, especially in the HPFH-2 mutation, since one sample was found with a value of $10.0 \%$ for $\mathrm{Hb} \mathrm{F}$. These data may reflect a possible intrinsic characteristic of the analyzed population. In the case of the Spanish $\delta \beta$-thalassemia mutation, levels of $\mathrm{Hb} F$ corroborate the values found in the literature concerning this mutation.

Besides the differences found in the $\mathrm{Hb} \mathrm{F}$ concentrations, differences were also observed in the results of conventional diagnostic tests for study groups. Differences in eryth- 
rocyte morphology showed that individuals with levels of $\mathrm{Hb} \mathrm{F}$ between 2 and $15 \%$ present greater frequency of moderate alterations, although not statistically significant; furthermore, the individuals with concentrations of $\mathrm{Hb} \mathrm{F}$ higher than $15 \%$ of total hemoglobin showed a predominance of mild morphological alterations. This result was not expected for this group, since samples with values of $\mathrm{Hb}$ F suggesting the presence of HPFH mutations have normal red blood cells (Hoyer et al., 2002). This same group showed the highest number of heterozygotes for the two HPFH investigated mutations, indicating that individuals without hemoglobin alterations who are carrying mutations may have alterations in erythrocyte morphology and globular osmotic resistance, a fact that can also be associated with intrinsic characteristics of the studied population. Based on the quantification of $\gamma$-globin chains, our findings corroborate the literature regarding the prevalence of $\gamma^{\mathrm{A}}$ chains in adult life (Zago et al., 2004).

The presence of heterozygotes for both HPFH mutations and for Spanish $\delta \beta$ thalassemia in this study confirms data concerning the formation of the Brazilian population and reinforces the influence of mixing processes, especially with regard to African ethnic groups, whereas mutations of African origin were more frequent in relation to Mediterranean origin. Among the many immigrants who have come to Brazil, there was an excess of black immigrants who, jointly with Amerindian and European, give rise to tri-hybrid population (Pena et al., 2000).

The absence of the Sicilian $\delta \beta$-thalassemia mutation in the study groups indicates that this genetic factor is not associated with increased expression of $\gamma$ genes in the sample population. This observation suggests that other mutations related to increased levels of $\mathrm{Hb}$ $\mathrm{F}$ in adults should be assessed. We conclude that the HPFH mutations have a greater influence in the Brazilian population than $\delta \beta$-thalassemia mutations. Hb F levels in heterozygous individuals carrying HPFH mutations vary from 10.0 to $38.1 \%$. The presence of these findings suggests the influence of African and European ethnicities and consequent mixing, which occurred during the formation of the Brazilian population.

\section{ACKNOWLEDGMENTS}

We would like to thank Fundação de Amparo à Pesquisa do Estado de São Paulo (grant \#2007/07887-0) and Conselho Nacional de Desenvolvimento Científico e Tecnológico (grant \#130607/2009-6) for financial support.

\section{REFERENCES}

Alter BP, Goff SC, Efremov GD, Gravely ME, et al. (1980). Globin chain electrophoresis: a new approach to the determination of the G gamma/A gamma ratio in fetal haemoglobin and to studies of globin synthesis. $B r . J$. Haematol. 44: 527-534.

Bonini-Domingos CR (2006). Metodologias Laboratoriais para o Diagnóstico de Hemoglobinopatias e Talassemia. $1^{\text {a }}$ ed. HN Press, São José do Rio Preto.

Craig JE, Barnetson RA, Prior J, Raven JL, et al. (1994). Rapid detection of deletions causing delta beta thalassemia and hereditary persistence of fetal hemoglobin by enzymatic amplification. Blood 83: 1673-1682.

Forget BG (1998). Molecular basis of hereditary persistence of fetal hemoglobin. Ann. N. Y. Acad. Sci. 850: 38-44.

Galanello R and Cao A (1998). Relationship between genotype and phenotype. Thalassemia intermedia. Ann. N. Y. Acad. Sci. 850: 325-333.

Gibney GT, Panhuysen CI, So JC, Ma ES, et al. (2008). Variation and heritability of Hb F and F-cells among betathalassemia heterozygotes in Hong Kong. Am. J. Hematol. 83: 458-464. 
Grosso M, Amendolara M, Rescigno G, Danise P, et al. (2008). Delayed decline of gamma-globin expression in infant age associated with the presence of Ggamma-158 $(\mathrm{C} \rightarrow \mathrm{T})$ polymorphism. Int. J. Lab. Hematol. 30: 191-195.

Hoyer JD, Penz CS, Fairbanks VF, Hanson CA, et al. (2002). Flow cytometric measurement of hemoglobin F in RBCs: diagnostic usefulness in the distinction of hereditary persistence of fetal hemoglobin (HPFH) and hemoglobin S-hPFH from other conditions with elevated levels of hemoglobin F. Am. J. Clin. Pathol. 117: 857-863.

Huisman HJ, Carver MFH, Baysal E and Efremov GD (1996). HbVar: A Database of Human Hemoglobin Variants and Thalassemias. Summaries of Mutation Categories. Pennsylvania University USA and McMaster University in Canada. Available at [http://globin.cse.psu.edu/]. Accessed April 26, 2010.

Marengo-Rowe AJ (1965). Rapid electrophoresis and quantitation of haemoglobins on cellulose acetate. J. Clin. Pathol. 18: 790-792.

Nussbaum RL, McInnes RR and Willard HF (2008). Thompson \& Thompson: Genética Médica. $7^{\mathrm{a}}$ ed. Elsevier Press, Rio de Janeiro.

Old JM (2003). Screening and genetic diagnosis of haemoglobin disorders. Blood Rev. 17: 43-53.

Pena SD, Macedo AM, Gontijo NF, Medeiros AM, et al. (1991). DNA bioprints: simple nonisotopic DNA fingerprints with biotinylated probes. Electrophoresis 12: 146-152.

Pena SD, Carvalho-Silva DR, Alves-Silva J and Prado VF (2000). Retrato molecular do Brasil. Ciênc. Hoje 27: 16-25.

Silvestroni E and Bianco I (1975). Screening for microcytemia in Italy: analysis of data collected in the past 30 years. $\mathrm{Am}$. J. Hum. Genet. 27: 198-212.

Stamatoyannopoulos G and Nienhuis AW (1994). Hemoglobin Switching. In: The Molecular Basis of Blood Diseases. 2nd edn. (Stamatoyannopoulos G, Nienhuis AW, Majerus PW and Varmus H, eds.). WB Saunders Company Press, Philadelphia, 107-155.

Steinberg MH (2009). Genetic etiologies for phenotypic diversity in sickle cell anemia. Sci. World J. 9: 46-67.

Thein SL (2005). Genetic modifiers of beta-thalassemia. Haematologica 90: 649-660.

Vella F (1968). Acid-agar gel electrophoresis of human hemoglobins. Am. J. Clin. Pathol. 49: 440-442.

Vives-Corrons JL, Pujades MA and Miguel A (1991). Screening of Spanish $(\delta \beta 0)$ thalassemia by polimerase chain reaction (PCR). Combined Meeting of British Society for Haematology and British Society for Haemostasis and Thrombosis, Glasgow, March 20-22, 1991, Abstracts. Br. J. Haematol. 77 (Suppl 1): 1-84.

Weatherall DJ (2001). Phenotype-genotype relationships in monogenic disease: lessons from the thalassaemias. Nat. Rev. Genet. 2: 245-255.

Weatherall DJ and Clegg JB (2001). The Thalassemia Syndromes. 4th edn. Oxford Blackwell Science, England.

Zago MA, Falcão RP and Pasquini R (2004). Hematologia: Fundamentos e Prática. $1^{\text {a }}$ ed. Ateneu Press, São Paulo. 